greater than in cases of the positive, first type. This type will be often met in its extreme form in Class II, Division 1, cases. Much of the difficulty of retention of these cases is due to these subnormally functioning facial muscles. In treating this type, only endless patience and double vigilance will avail. Retention can be proved sufficient only by years of care and months of waiting after removing each part, for the whole organization lacks the metabolic and functional tone which makes for permanency in orthodontic correction.

(To be continued.)

\title{
A PECULIAR ACCIDENT
}

By Frederick S. McKay, D.D.S., Colorado Springs, Colo.

THE case with which this short article deals, was the victim of such a peculiar 1 accident, if such it could be called, or to express it in better terms, so peculiar an experience, that it has been deemed worthy of description.

The lad of about nine years of age had been raised with difficulty and was in every sense of the term undeveloped which was in no way more conspicuously evident than in the dental arches.

It was a matter of apprehension to his parents and physician that the function of mastication was almost suspended, for as expressed by them it was "too queer to see him eat."

Judging from the occlusion it is evident that most of the masticatory func-

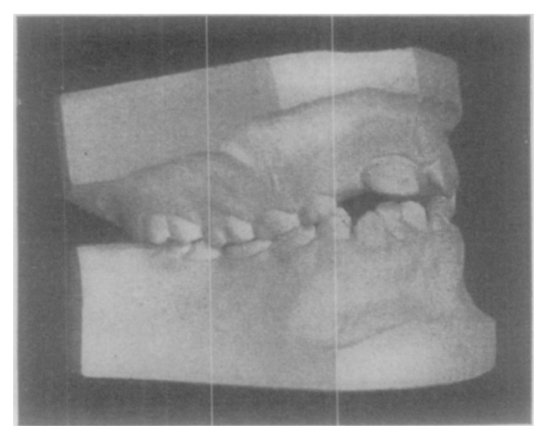

Fig. 1.

tion was performed upon the right side (Fig. 1), either because of the shortening of the vertical height of the arches on the left which allowed the cusps of the upper molars to close almost onto the gingival margins of the lowers, or else because of the tumefied condition of the gums on that. side, which rendered mastication uncomfortable if not actually painful (Fig. 2, A and B).

The probabilities are that there were two distinct causes as above outlined, each sufficient in itself and yet intensifying each other.

When the case was first seen it was evident that the condition of the gums upon the left side was due to the presence of subgingival calcular deposits, plainly visible, upon the temporary molars, and more and more am I becoming impressed, 
after continued otservation. that. as a rule, orthertuntive fail to ronguize gin gival irritations befure commcelling trealmomt.

From the presemt standprsint in vicwing the signiticance wi these carly gin.

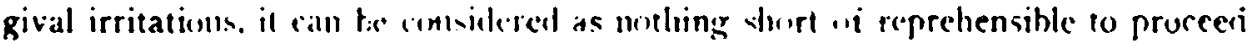
with the placing of appliance: " itlkent fir-l planing sumoth the rongh etched sut: facc of the cnamel just unter the gums abd in the interproximal spaces. with the well-known plane? which are aldibble fur this purpose, or referring the patient into the proper hands ior such service

The criticisns: of the genceal practitioner regarding the irritation of orthodontia appliances have been 1 cll meritert, and in my estimation these irritation

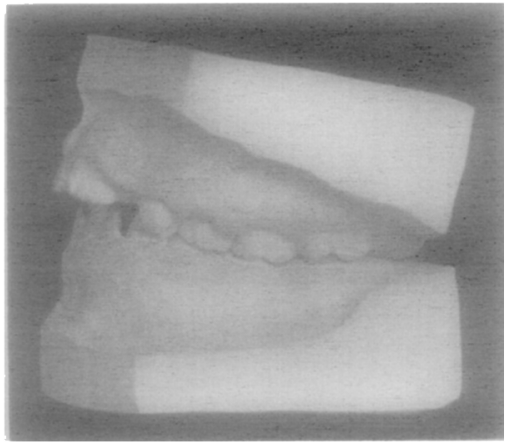

Fig. 2-A.

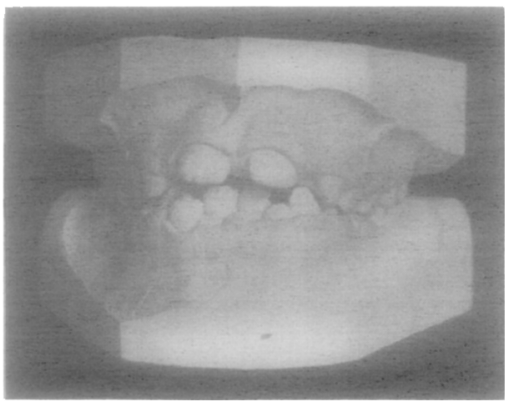

Fig. 3.

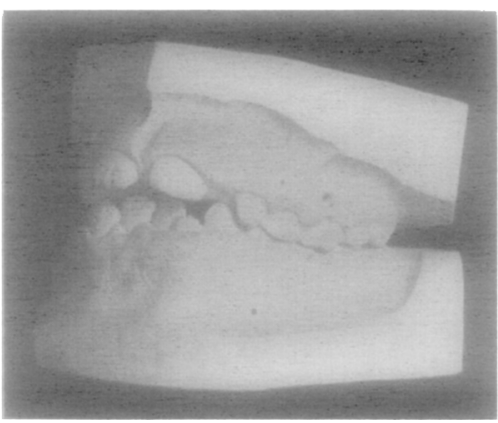

Fig. 2-B.

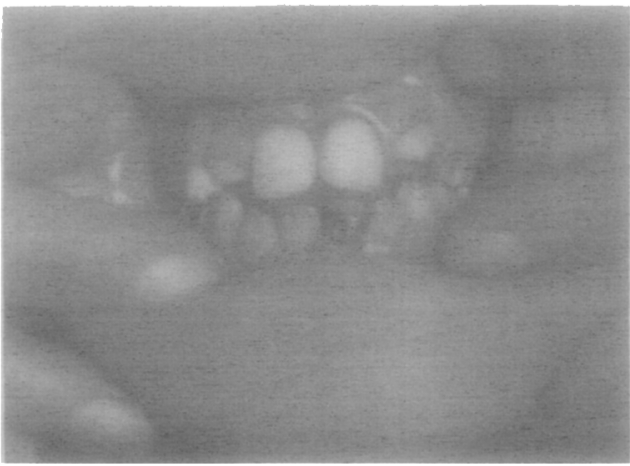

Fig. 4.

have been largely due to failure to properly administer this subginuival treatment.

'To proceed, however, with the story; the treatment for enlargement of the dental arches was carried on during the winter and spring months and refainers were placed just before the boy was taken to a mountain resort for the summer.

During an exhibition the lad fell off a grandstand and both permanent upper central incisors were knocked out of the mouth onto the ground.

They were picked up and the boy taken to the dentist in the little mountain town who cleansed the dislodged teeth. opened the pulp canals, removed the contents, and filled the camals, and then reinserted the teeth into the sockets and ligated them to the retainer. 
In replanting the teeth, however, in some unexplainable way they were transposed, the left one being put into the socket of the right side and vice versa, and I saw him about two weeks after the accident they had become quite firm, so that their transferal to proper position was deemed unwise. Fig. 3 shows the case as it was originally. Fig. 4 shows the present appearance, and there they must remain for how long we don't know, but the history of such cases seems to be that their loss will eventually occur through absorption of the roots.

\title{
THE PRINCIPLES OF ANCHORAGE
}

\author{
By Martin Dewey, D.D.S., M.D., Kansas City, Mo. \\ Professor of Dental Anatomy and Orthodontia, Kansas City Dental College; \\ President of The Dewey School of Orthodontia.
}

PROBABLY no division of orthodontia requires as much attention or has $P$ been responsible for so many failures as anchorage. Only during the last few years have practitioners of orthodontia reached a point where they have been able to classify anchorage according to certain principles and always have some definite idea in view in the construction of the appliance, so as to follow out fundamental laws. In the movement of the malposed teeth, the most important thing to consider in the beginning is the question of anchorage. Angle states, "The movement of one or more teeth in any of the several directions is possible only by the exercising of force and its intelligent application in accordance with the laws of the mechanics and dynamics. . . . According to the well-known laws of physics, action and reaction are equal and opposite, hence it must follow that the resistance of the anchorage must be greater than that offered by the tooth to be moved, otherwise there will be displacement of the anchorage and failure in the movement of the teeth to the extent, or, probably, in the direction desired." Guilford" also states that, "The use of force for overcoming resistance and causing malposed teeth to assume their proper position falls within the domain of that branch of physics known as dynamic.

The movement of the teeth like the movement of other bodies is regulated and controlled by certain general principles or laws, the proper understanding of such of them as are important to us in our work is necessary in order that the required operation may be performed intelligently and in a scientific manner." It is therefore seen that the writers recognized that anchorage had to deal with certain mechanical forces which are recognized in other branches of mechanics. Angle and Guilford both refer to the old physical law, namely, action and reaction are always equal and opposite. In other words, just as much force as is exerted on the malposed tooth must be overcome by the anchorage.

If we had an unlimited field to work in or could make conditions or construct our anchorage according to our desires there would not be so many difficulties encountered in the movement of malposed teeth. However some of the difficulties which we have to encounter are summed up again by Guilford in which he says: "To construct a machine which by its action will accomplish a desired result may be easy, but to devise one that will give us the best results,

1Guilford: Orthodontia, 4th edition. 